\title{
Efeitos da endotelina-1 sobre a esteroidogênese e o crescimento celular em cultura de células da granulosa de bovinos
}

Luis Henrique MONTREZOR ${ }^{1,2}$

Alzira Amélia Martins ROSA E SILVA ${ }^{1}$

\section{Correspondência para:} LUIS HENRIQUEMONTREZOR Rua João Paschoalin, $552-$ Ap. 01 Parque Bandeirantes 14090-420 - Ribeirão Preto - SP montrezorlh@ig.com.br

Recebido para publicação: 15/07/2004 Aprovado para publicação: 13/07/2005

1 - Departamento de Fisiologia da Faculdade de Medicina de Ribeirão Preto da Universidade de São Paulo, Ribeirão Preto - SP

2 - Centro Universitário Barão de Mauá, Ribeirão Preto - SP

\section{Resumo}

Palavras-chave: Esteroidogênese. Células das granulosas. Bovinos.

Além do controle neuroendócrino do eixo hipotalâmico-hipofisáriogonadal existem fatores autócrinos e parácrinos que controlam o crescimento, seleção e ovulação nos mamíferos. Estes fatores ainda não estão bem estabelecidos. Objetivando analisar as variações nas concentrações plasmáticas da endotelina-1 em um ciclo estral bovino e seus efeitos sobre o cultivo de células da granulosa, foram analisadas amostras plasmáticas de 5 dias $(0,1,3,7$ e 13$)$ de um ciclo estral, tendo como base o dia da ovulação (dia 0) e 3 horas $\left(8,13\right.$ e 16) do $14^{\circ}$ dia do ciclo. As variações nas concentrações plasmáticas de endotelina-1 não foram significativas para os dias assim como para as horas do dia analisado. Células da granulosa obtidas de folículos antrais foram cultivadas durante 48 horas com diferentes concentrações de endotelina. Os resultados demonstraram que a endotelina atua de maneira dosedependente estimulando a produção de progesterona e inibindo o crescimento celular.

\section{Introdução}

A endotelina-1 (ET-1) é membro da família de peptídeos vasoconstritores isolada originalmente de células endoteliais suínas ${ }^{1}$. A ET apresenta amplas ações fisiológicas no sistema endócrino como inibidora da liberação de renina ${ }^{2}$, indutora da liberação de peptídeo natriurético atrial $(\mathrm{ANP})^{3}$, indutora da liberação de eicosanóides ${ }^{4}$, de vasopressina, de epinefrina ${ }^{5}$ e de peptídeo vasoativo intestinal ${ }^{6}$. A ET-1 foi identificada em corpo lúteo (CL) de $\operatorname{ratas}^{7}$ e sabe-se que esse peptídeo estimula a atividade de DNA polimerase ovariana sem afetar a produção de $\mathrm{DNA}^{8}$ assim como inibe a luteinização das células da granulosa (CG), pois inibe a estimulação de hormônio luteinizante $(\mathrm{LH})^{9}$. A produção de progesterona $\left(\mathrm{P}_{4}\right)$ das $C G$ é modulada por fatores de crescimento e citocinas. Por exemplo, fator de crescimento epidermal (EGF), fator de crescimento fibroblástico (FGF) e interleucina-1 (IL-1) inibem a produção de $\mathrm{P}_{4}$ em cultura de $\mathrm{CG}^{10,11}$. Contudo, o fator de crescimento semelhante à insulina-1 (IGF-I) aumenta a produção de $\mathrm{P}_{4}$ pelas $\mathrm{CG}$ suínas, estimuladas pelo $\mathrm{LH}^{12}$; o fator de crescimento derivado de plaquetas (PDGF) aumenta a produção de $\mathrm{P}_{4}$ em CG de ratas estimuladas com hormônio folículo estimulante $(\mathrm{FSH})^{13}$. Os objetivos do presente trabalho foram examinar os efeitos da ET-1 sobre a esteroidogênese e a proliferação celular em cultura de CG bovinas. Também analisamos a concentração plasmática da ET-1 durante 5 dias de um ciclo estral bovino.

\section{Materiais e Métodos}

Efeitos in vitro da et-1 sobre a concentração de progesterona e proliferação de células da granulosa

Os ovários foram obtidos em matadouros e transportados até o laboratório em solução salina com tampão fosfato (PBS) a $37^{\circ} \mathrm{C}$. Os folículos foram 
escolhidos de acordo com observações macroscópicas: tamanho (entre 5 e 8 milímetros de diâmetro), coloração do fluido folicular e vascularização. Após serem dissecados cuidadosamente com auxílio de lupa, os mesmos foram invertidos para raspagem da parede interna e obtenção das CG. Essas células foram centrifugadas 3 vezes a $1100 \mathrm{rpm}$ por 10 minutos em meio H-199 composto por meio TCM-199 suplementado com 29,71 mM de Hepes, 50 $\mathrm{mg} / \mathrm{mL}$ de gentamicina e $10 \%$ de soro fetal bovino (meio de manipulação). Após as centrifugações determinou-se o número de células viáveis através do método de exclusão do Trypan blue e contagem em câmara de Neubauer. Utilizou-se 200.000 células em 1 mL de Meio B-199 (meio de cultura), composto por Meio TCM-199 suplementado com 28,57 mM de bicarbonato de sódio, 2,73 $\mathrm{mM}$ de piruvato de sódio, $16,78 \mathrm{mM}$ de Hepes, $50 \mathrm{mg} / \mathrm{mL}$ de gentamicina e $10 \%$ de soro fetal bovino, com diferentes concentrações de ET-1 $\left(0,10^{-10}, 10^{-9}, 10^{-8} \mathrm{e}\right.$ $\left.10^{-7} \mathrm{M}\right), 144 \mathrm{ng} / \mathrm{mL}$ de testosterona $(\mathrm{T})$ e 1 UI de gonadotrofina coriônica humana (hCG). As placas foram incubadas em estufa a $37^{\circ} \mathrm{C}$ com $5 \%$ de $\mathrm{CO}$, por um período de 48 horas $^{14}$, ou por diferentes períodos quando especificados. A dosagem de progesterona $\left(\mathrm{P}_{4}\right)$ no meio foi realizada pelo método de radioimunoensaio (RIE) e a contagem celular foi realizada em câmara de Neubauer, após as células serem descoladas do fundo dos poços por tratamento com $0,5 \mathrm{~mL}$ de solução de tripsina a $0,25 \%$ em PBS por 10 minutos a $25^{\circ} \mathrm{C}^{15}$.

Estudo in vivo de esteróides, hormônios protéicos e et-1 durante o ciclo estral

Foram utilizadas 12 vacas mestiças adultas (Girolandas) com idades entre 2,5 a 4 anos sincronizadas com 2 aplicações intramusculares (i.m) de prostaglandina $\mathrm{F}_{2 \alpha}$ $\left(\right.$ PGF $\left._{2 \alpha}\right)\left(\right.$ Ciosin $\left.^{\circledR}\right)$. Após 72 horas da segunda aplicação foram observados os sinais de cio nas vacas. O crescimento folicular, a ovulação e a presença de corpo lúteo (CL) foram analisados pela palpação transretal. As colheitas de sangue foram realizadas às 8 horas da manhã nos dias 0,1 , 3, 7 e 13 de um ciclo estral (sendo o dia zero o suposto dia da ovulação) e às 8,13 e 16 horas de um dia do ciclo (14 ${ }^{\circ}$ dia). O sangue foi centrifugado a $1600 \mathrm{x}$ g por 15 minutos em centrífuga refrigerada a $4^{\circ} \mathrm{C}$ e o plasma estocado a $-20^{\circ} \mathrm{C}$ para posteriores dosagens de estradiol $\left(\mathrm{E}_{2}\right)$, hormônio luteinizante (LH), $\mathrm{P}_{4}$ e ET-1 através do método de RIE. Os esteróides foram determinados pelo método de Bélanger, Caron e Picard ${ }^{16}$ e modificado por Rosa e Silva et al. ${ }^{17}$. O LH pelo método de RIE $^{18}$ e a ET-1 com kits comerciais da Peninsula Laboratories - US A.

\section{Análises estatísticas}

O experimento para contagem celular e produção de $\mathrm{P}_{4}$ in vitro foi analisado através de um delineamento inteiramente casualizado (DIC), num esquema fatorial $2 \times 5$, duas situações para hCG (sem hCG e 1 UI de hCG) e cinco níveis de ET-1 $\left(0,10^{-10}, 10^{-9}\right.$, $10^{-8}$ e $\left.10^{-7} \mathrm{M}\right)$. As variações plasmáticas in vivo de $\mathrm{E}_{2}, \mathrm{LH}, \mathrm{P}_{4}$ e ET-1 durante 5 dias $(0$, $1,3,7$ e 13) do ciclo estral e dentro de três horas $(8,13$ e 16) de um dia do ciclo foram estudadas por uma análise de regressão em função do tempo. Todas as médias foram submetidas ao teste de Tukey e todos os dados estudados foram analisados pelo programa computacional SAS, sendo considerado estatisticamente significativo $\mathrm{p}<0,05$.

\section{Resultados}

Os dados apresentados na figura 1 mostram os efeitos de diferentes concentrações de ET-1 sobre o crescimento celular e sobre a produção de $\mathrm{P}_{4}$ em cultura de CG de ovários bovinos. Nota-se aumento médio na concentração de $\mathrm{P}_{4}$ concomitante ao aumento na concentração de ET-1. A maior concentração média de $\mathrm{P}_{4}(59,25 \mathrm{ng} /$ $\mathrm{mL}$ ) foi observada quando utilizou-se a maior concentração de ET-1 $\left(10^{-7} \mathrm{M}\right)$. Na ausência de ET-1 observa-se a menor 


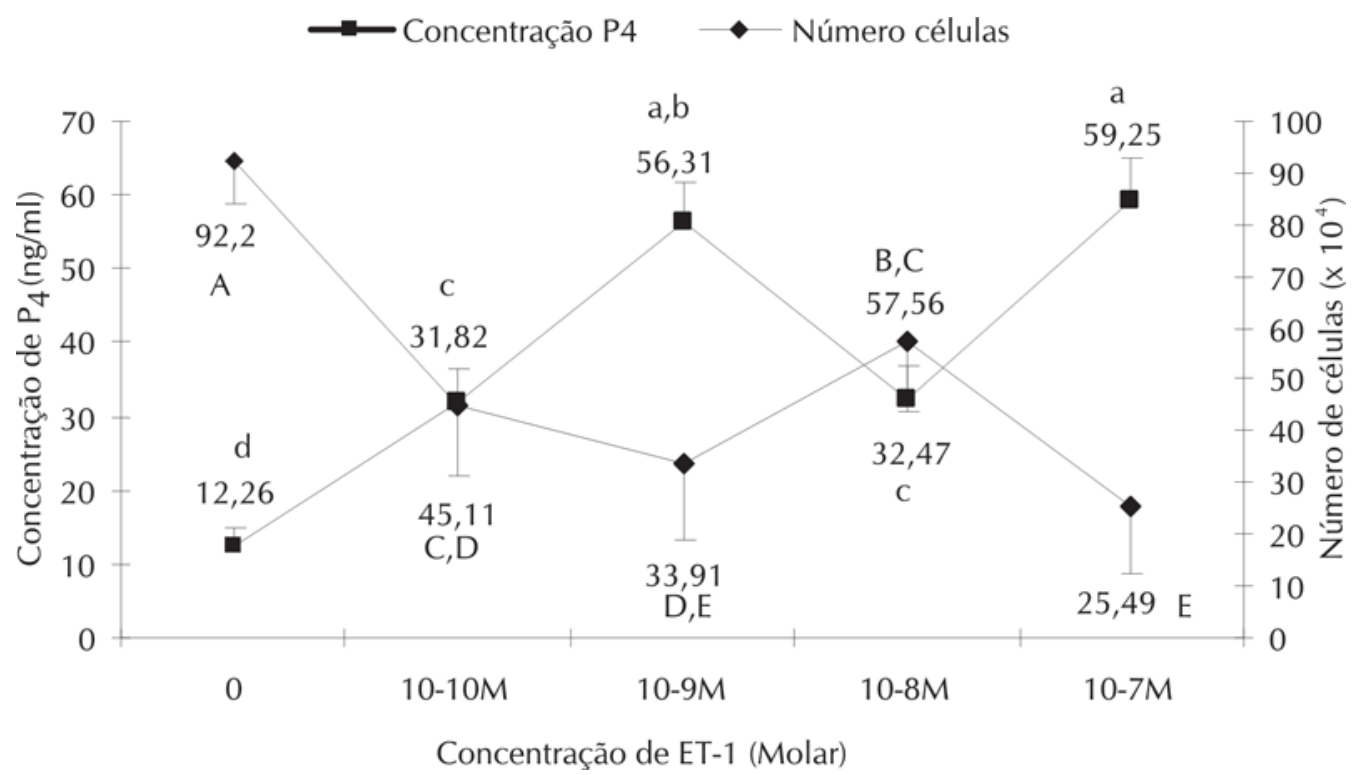

Figura 1- Efeito de diferentes concentrações de ET-1 sobre o crescimento celular e produção de $\mathrm{P}_{4}$ em cultura de CG de ovários bovinos durante 48 horas de cultivo. Letras diferentes na mesma linha diferem significativamente $(p<0.05)$

concentração média de progesterona (12,26 $\mathrm{ng} / \mathrm{mL})$. O número médio de células viáveis também foi alterado significativamente pelas variações nas concentrações de ET-1. Observa-se maior número médio de células $\left(92,20 \times 10^{4}\right)$ na ausência da ET-1. Com a maior concentração de ET-1 $\left(10^{-7} \mathrm{M}\right)$ notase o menor número médio de CG viáveis $\left(25,49 \times 10^{4}\right)$.

Os resultados apresentados nas figuras 2 e 3 mostram as variações plasmáticas médias de LH, $\mathrm{E}_{2}, \mathrm{P}_{4}$ e ET-1 durante 5 dias $(0,1,3,7$ e 13) de um ciclo estral bovino. No painel A da figura 2 observa-se as variações plasmáticas médias do LH. Esse hormônio apresentou maior concentração plasmática média $(2,81 \mathrm{ng} / \mathrm{mL})$ no primeiro dia analisado, o dia zero, onde ocorre o pico de LH plasmático que decresce, posteriormente, durante os quatro dias seguintes, atingindo a menor concentração méida $(0,57 \mathrm{ng} / \mathrm{mL})$ no $13^{\circ}$ dia. As variações plasmáticas médias de $\mathrm{E}_{2}$ são observadas no painel B. Observa-se a maior concentração média $(8,53 \mathrm{ng} / \mathrm{mL})$ no dia zero do ciclo, decrescendo posteriormente até o décimo $(3,27 \mathrm{ng} / \mathrm{mL})$ terceiro dia do ciclo. O painel A da figura 3 mostra as variações observadas nas concentrações plasmáticas médias da $\mathrm{P}_{4}$. Nota-se que houve aumento progressivo na concentração média desse hormônio durante os dias analisados. No $7^{\circ}$ dia observa-se significativo aumento $(2,05 \mathrm{ng} / \mathrm{mL})$ da $\mathrm{P}_{4}$ plasmática em relação aos 3 dias anteriores. Esse aumento é contínuo até o $13^{\circ}$ dia onde se nota a maior concentração média $(2,49 \mathrm{ng} / \mathrm{mL})$. As variações plasmáticas médias de ET-1 podem ser observadas no painel B da figura 3. Não há variações significativas durante os dias analisados. A menor concentração plasmática $(1,33 \mathrm{ng} / \mathrm{mL})$ foi observada no dia zero e a maior concentração $(2,32 \mathrm{ng} / \mathrm{mL})$ de ET-1 no dia 1. Nota-se elevação gradual da concentração de ET-1, a partir do dia 7 em direção ao dia 13 do ciclo estral.

Nas figuras 4 e 5 observam-se as variações plasmáticas médias de $\mathrm{LH}, \mathrm{E}_{2}, \mathrm{P}_{4} \mathrm{e}$ ET-1 durante 3 horas $\left(8,13\right.$ e 16) do $13^{\circ}$ dia do ciclo estral. Não houve variações significativas para os hormônios analisados.

\section{Discussão}

A ET-1 foi identificada em corpo lúteo de ratas e sua presença no ovário induziu atividade da DNA polimerase sem 
A

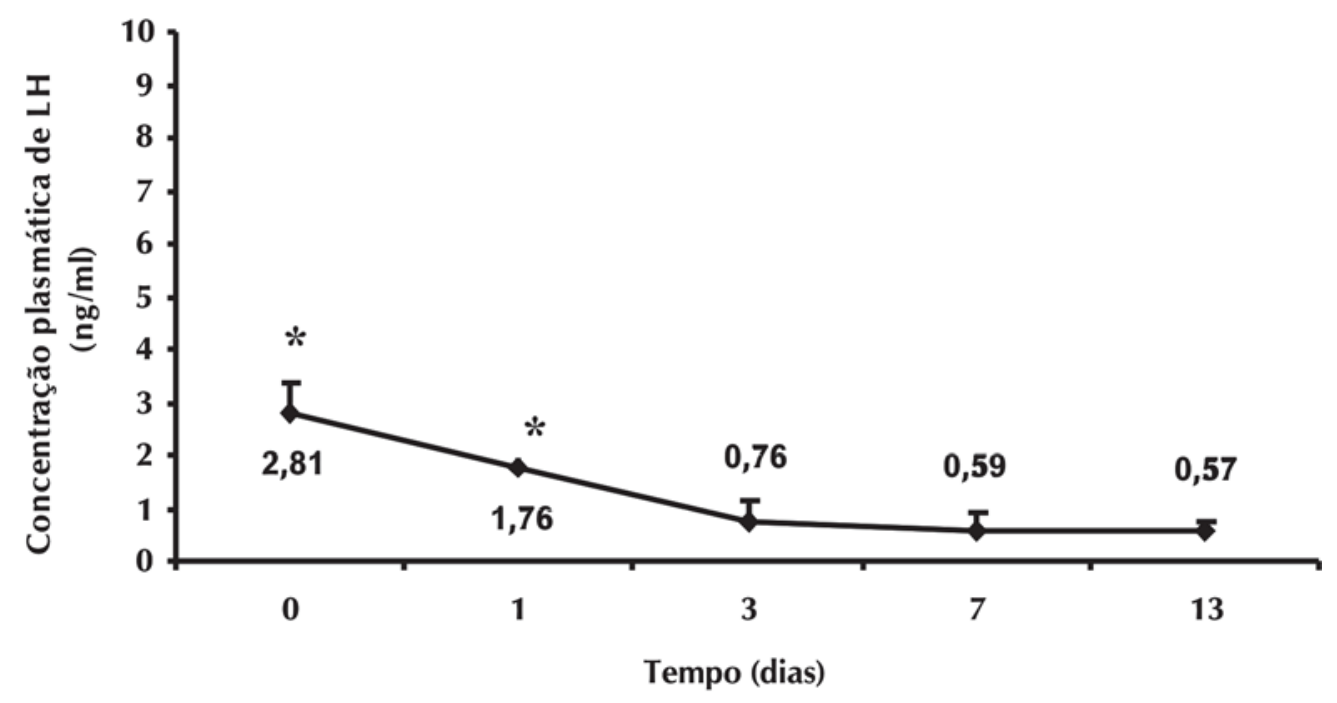

B

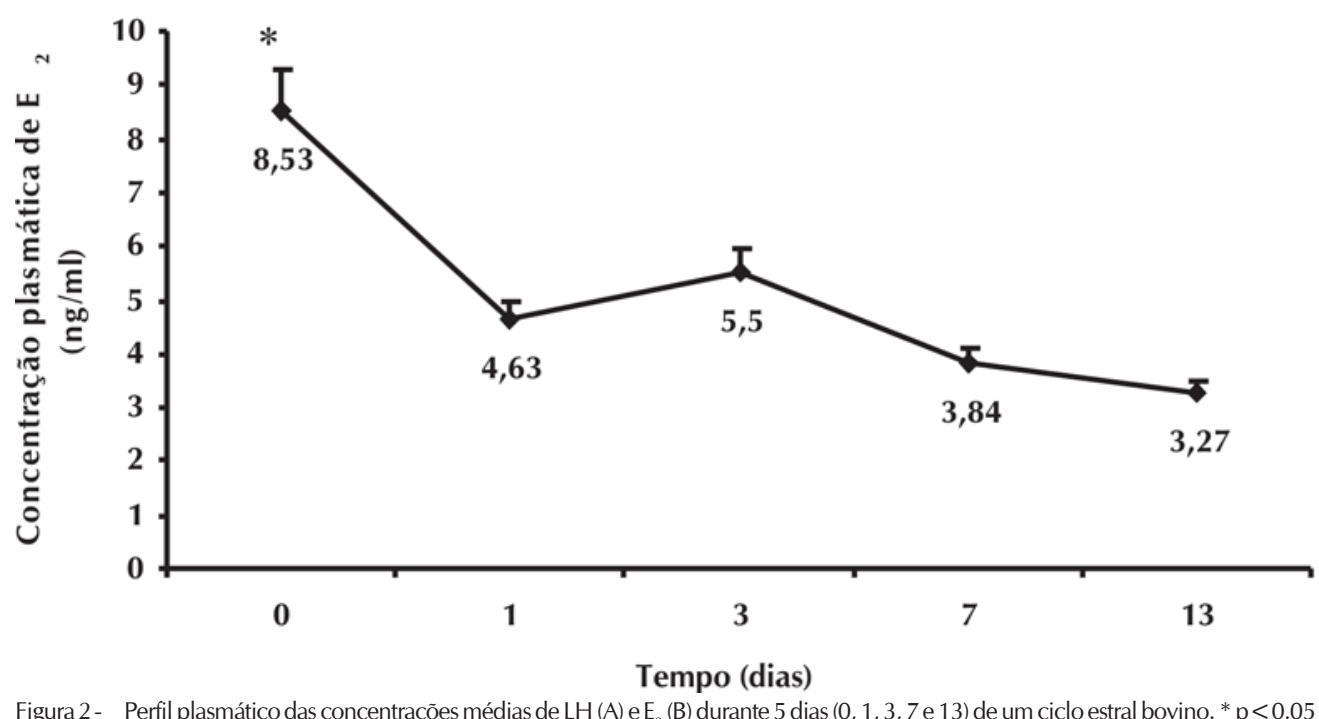


A

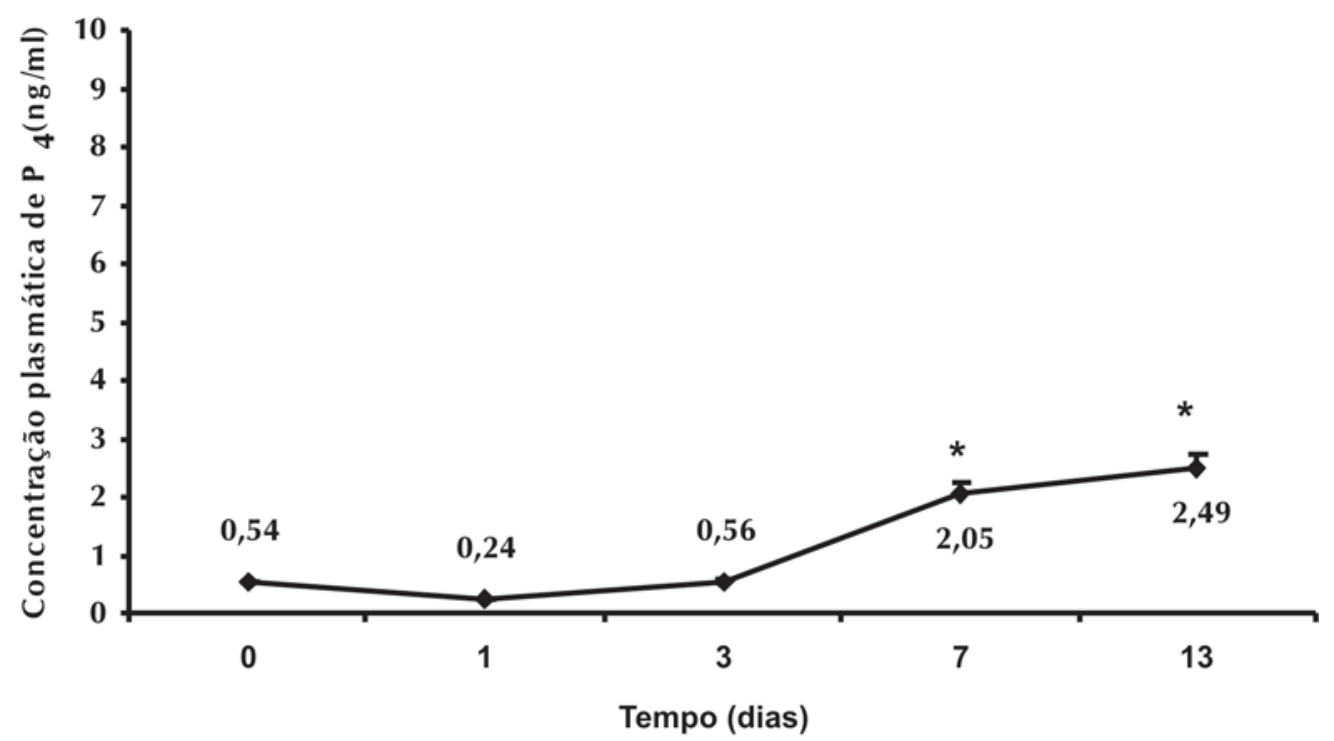

B

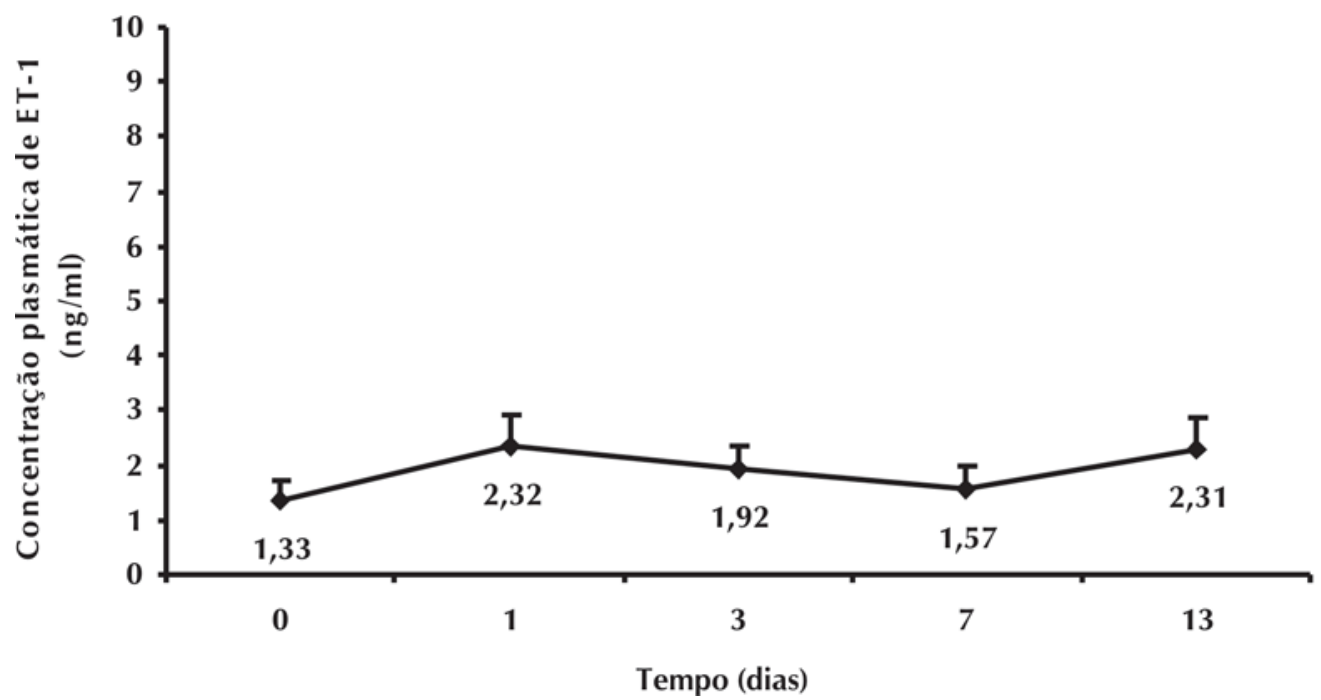

Figura 3 - Perfil plasmático das concentrações médias de $\mathrm{P}_{4}$ (A) eET-1 (B) durante 5 dias $(0,1,3,7$ e 13$)$ de um ciclo estral bovino. ${ }^{*}$ p $<0.05$ 


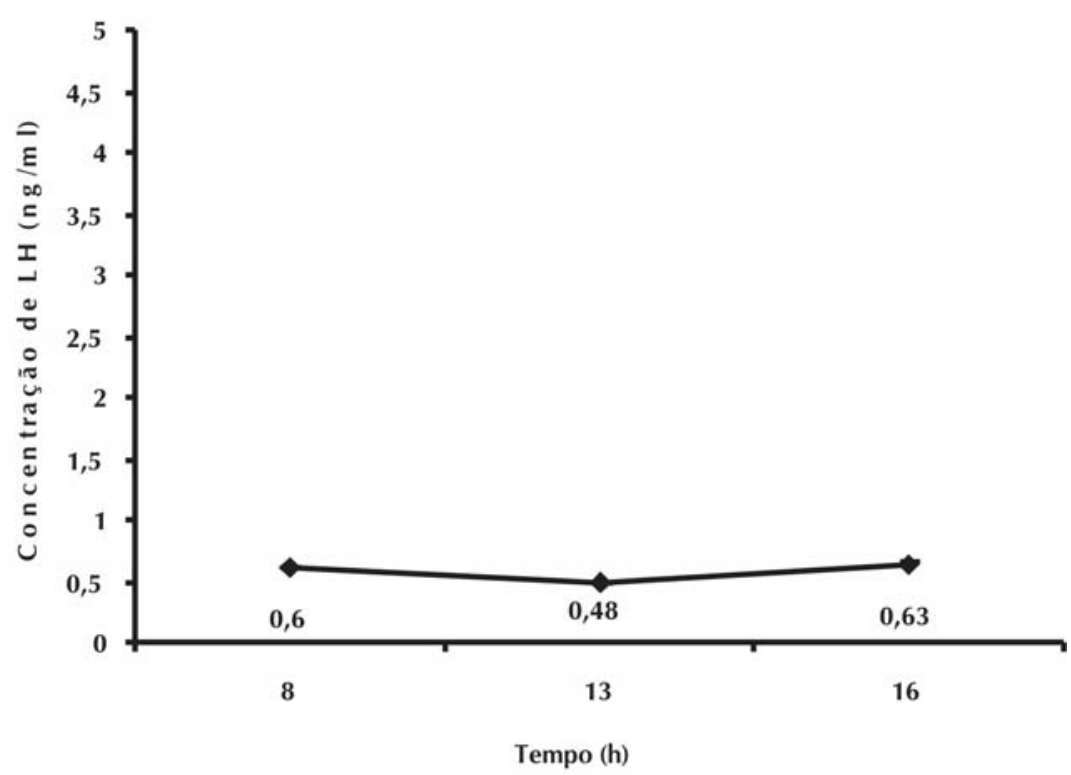

B

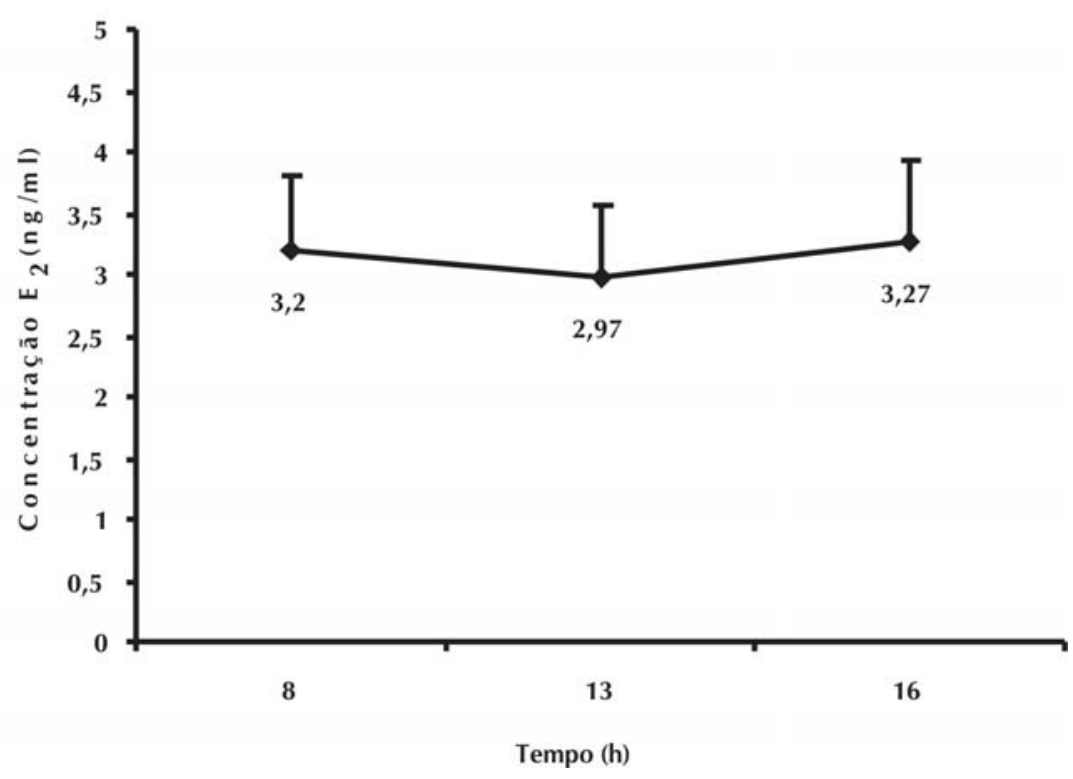

Figura 4 - Perfil plasmático das concentrações médias de $\mathrm{LH}(\mathrm{A})$ e $\mathrm{E}_{2}$ (B) durante 3 horas $\left(8,13\right.$ e 16) de um dia $\left(14^{\circ}\right)$ do ciclo estral bovino 

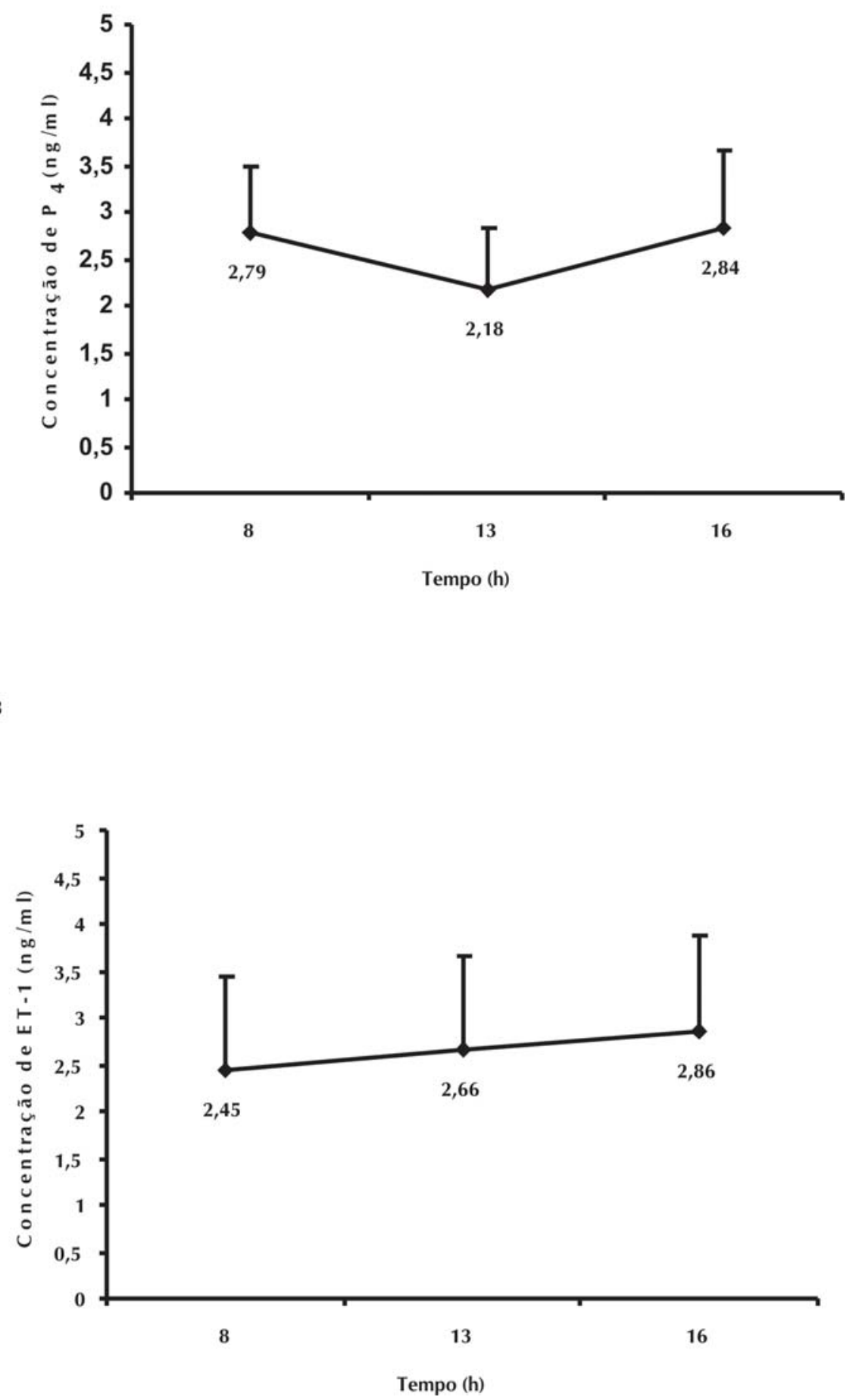

Figura 5 - Perfil plasmático das concentrações médias de $\mathrm{P}_{4}$ (A) e ET-1 (B) durante 3 horas (8, 13 e 16$)$ de um dia $\left(14^{\circ}\right)$ do ciclo estral bovino 
afetar a produção de $\mathrm{DNA}^{7}$; assim como pode ter um papel fisiólogico in vivo, que estaria relacionado à inibição da luteinização das CG de suínos, até ocorrer a ovulação, por meio da inibição do acúmulo de $\mathrm{P}_{4}$ e AMPc, estimulados pelo $\mathrm{LH}^{9}$. A ET-1 age, predominantemente, sobre receptores ETA existentes nas células da granulosa luteinizadas em humanos ${ }^{19}$. Estudos demonstraram que a ET-1 possui um efeito estimulatório sobre o crescimento de células do estroma e do endométrio de ovinos ${ }^{20}$. Os trabalhos citados pela literatura utilizaram FSH no meio de cultura, neste trabalho não foi utilizada essa gonadotrofina podendo, portanto, ser esse um dos fatores responsáveis pelas respostas opostas às observadas na literatura. Além disso, o desenho experimental, a densidade celular, o tamanho dos folículos, o grau de diferenciação celular, o tipo celular e a espécie estudada também são diferentes.

Em nosso trabalho, na ausência de ET-1, obteve-se a menor concentração média de $\mathrm{P}_{4}$ e a medida em que se aumenta a concentração da ET-1 na cultura aumentase a produção desse hormônio, o qual apresenta maior concentração média na presença da maior concentração de ET-1. Nota-se também efeito inibidor da ET-1 sobre o crescimento celular. $\mathrm{Na}$ ausência de ET-1 observa-se o maior número médio de células e na maior concentração de ET1, nota-se o menor número médio de células. Ambos resultados demonstram que as ações da ET-1 sobre as CG de bovinos acontece de maneira dose-dependente, inibindo o crescimento celular e estimulando a síntese de $\mathrm{P}_{4}$. A ET-1 provocou um leve, porém significativo, aumento na secreção de $\mathrm{P}_{4}$, mas não na produção de $\mathrm{E}_{2}$. $\mathrm{O}$ efeito estimulatório na secreção de $\mathrm{P}_{4}$ foi observado na ausência e presença de $\mathrm{FSH}^{21}$.

Gonadotrofinas, EGF, TGFa (Fator alfa de crescimento tumoral), bFGF, IGF-I e estrógenos são identificados como fatores de sobrevivência folicular capazes de suprimir a fragmentação do DNA celular. Por outro lado, andrógenos, interleucina 6
(IL-6), hormônio liberador de gonadotrofinas $(\mathrm{GnRH})$, pró-renina, angiotensina-II (A-II), dentre outros, são potentes fatores atretogênicos ${ }^{22}$. Ratas tratadas com gonadotrofina coriônica de égua prenhe (PMSG) apresentam aumento na concentração plasmática de $\mathrm{P}_{4}$. Em contraste, $\mathrm{O} \mathrm{E}_{2}$ plasmático declinou acentuadamente até atingir valores semelhantes ao controle. Esta alteração na esteroidogênese representada por uma relação E2/P4 baixa tem sido associada a variações que acompanham o início da atresia folicular ${ }^{23}$. Folículos bovinos nos quais as concentrações de andrógenos ou $\mathrm{P}_{4}$ no fluido folicular estão maiores do que os estrógenos ( $\mathrm{E}_{2}$ :TA (andrógenos totais) ou $\mathrm{E} 2 / \mathrm{P} 4<1,0)$, possuem características de folículos atrésicos ${ }^{24}$.

A seqüência exata dos eventos responsáveis pelo desencadeamento dos mecanismos que culminam com a apoptose das CG permanecem incertos. Entretanto, os sistemas que desencadeiam a apoptose estão associados com a ativação de uma

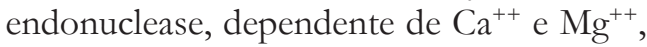
que cliva o DNA em fragmentos de oligonucleossomas. A ativação dessa enzima pode estar relacionada com as interações entre os fatores de sobrevivência e os fatores atretogênicos foliculares. Uma vez ativada a endonuclease o processo é irreversível ${ }^{22,23}$. Bovinos tratados com $\mathrm{P}_{4}$ apresentaram regressão do folículo dominante, confirmando a hipótese de que tratamento com $\mathrm{P}_{4}$ causa atresia do folículo dominante, sendo a apoptose um processo progressivo na instalação da atresia folicular. A regressão na atividade da aromatase está associada a diminuição na produção de $\mathrm{E}_{2}$, relacionado ao processo de atresia na maioria dos mamíferos. $\mathrm{A} \mathrm{P}_{4}$ induziu uma diminuição na atividade da aromatase, sem reduzir seu substrato (testosterona), aumentou o índice de apoptose e diminuiu o diâmetro folicular. Além disso, houve uma queda nas concentrações de IGF-I e aumento nas concentrações de proteínas transportadoras de IGF (IGFBP) no fluido folicular ${ }^{25}$. Essas alterações no fluido folicular podem estar 
diretamente associadas à redução na atividade da aromatase.

A ET-1, utilizada em nosso trabalho em CG de folículos antrais médios, pode ser um fator atretogênico ativador da endonuclease e/ou das IGFBP's culminando com a apoptose das CG, visto que a produção de $\mathrm{P}_{4}$ aumentou e o crescimento celular diminuiu, de maneira dosedependente. Folículos podem ser considerados saudáveis pela análise da relação $\mathrm{E}_{2} / \mathrm{P}_{4}$. Uma elevada taxa $\mathrm{E}_{2} / \mathrm{P}_{4}$ é característica de folículos saudáveis, sendo o inverso indicativo de atresia ${ }^{25}$. No mesmo trabalho, os autores observaram uma elevada taxa $\mathrm{P}_{4}: / \mathrm{E}_{2}$, em folículos bovinos, indicativo de atresia folicular. No presente trabalho a relação $\mathrm{P}_{4} / \mathrm{E}_{2}$ não foi realizada devido ao fato de não termos dosado o estradiol na cultura mas, segundo a literatura, pode-se esperar alteração na esteroidogênese, nesse desenho experimental, com diminuição da síntese de $\mathrm{E}_{2}$ e aumento da síntese de $\mathrm{P}_{4}$.

A regulação na secreção das gonadotrofinas durante o ciclo estral requer um delicado e preciso balanço entre complexas interações hormonais ${ }^{26}$. Na vaca, no final do período do cio ocorre a ovulação, caracterizada pela onda ovulatória de LH, seguida pela formação do corpo lúteo ${ }^{27}$. Mediante as análises dos perfis hormonais durante os 5 dias $(0,1,3,7$ e 13$)$ do ciclo estral bovino analisados, observase que a maior concentração plasmática média de LH foi verificada no dia zero, ou seja, este pico está caracterizado como sendo a onda ovulatória do LH. Nota-se que no dia zero, sendo o dia da ovulação, que é precedido pelo período de cio, o $\mathrm{E}_{2}$ apresenta sua maior concentração plasmática média. No ovário, sob ação de LH e FSH, dentre outros hormônios e fatores de crescimento esteroidais e não esteroidais, o período de estro é caracterizado por elevada secreção de estrógenos pelos folículos préovulatórios. Após a ovulação inicia-se a formação do corpo lúteo e secreção de $\mathrm{P}_{4}$ pelo mesmo, caracterizando a fase lútea do ciclo estral ${ }^{27}$. A maior concentração plasmática média de $\mathrm{P}_{4}$ ocorre no dia 13 , porém desde o dia 7 está significativamente maior. O pequeno aumento observado no dia zero pode estar relacionado com a necessidade de uma atividade da $\mathrm{P}_{4}$ plasmática para sensibilizar os gonadotrófos hipofisários para a liberação da onda ovulatória de $\mathrm{LH}^{27}$. A ET-1 sozinha tem um rápido efeito estimulador na liberação de $\mathrm{P}_{4}$ em CL bovinos perfundidos. Após uma segunda perfusão houve um rápido efeito inibidor. Além disso, após exposição das células à $\mathrm{PGF}_{2 \alpha}$, houve uma marcada supressão na secreção de $\mathrm{P}_{4}$. A PGF $\mathrm{PG}_{2 \alpha}$ estimulou a liberação de ET- $1^{28}$. Portanto, pode haver uma interação entre células luteínicas e endoteliais no mecanismo de início da luteólise funcional in vivo, onde a PGF $_{2 \alpha}$ estimula a liberação de ET-1 e esta potencia e acelera a cascata da luteólise in vivo. A concentração plasmática de ET-1 permaneceu basal entre os dias 2 e 12 do ciclo estral, aumentando do dia 13 ao dia 19 e alcançando a maior concentração entre os dias 20 e 22, após o estro. As menores concentrações de $\mathrm{P}_{4}$ foram observadas nos dias de maior concentração de ET-1, demonstrando inversa variação plasmática ${ }^{29}$. Segundo os autores estes resultados sugerem que a ET-1 luteínica é um mediador/ promotor da luteólise em bovinos.

As análises dos perfis hormonais de LH, $\mathrm{E}_{2}, \mathrm{P}_{4}$ e ET-1 durante 3 horas (8, 13 e 16) de um dia $\left(14^{\circ}\right.$ dia do ciclo) do ciclo estral bovino podem ser observadas nas figuras 4-A e B e 5-A e B, respectivamente. Não são observadas variações significativas dos hormônios estudados durante as horas analisadas. As maiores concentrações plasmáticas médias de $\mathrm{LH}, \mathrm{E}_{2}$ e $\mathrm{P}_{4}$ são observadas às 16 horas, enquanto suas menores concentrações são obtidas às 13 horas. A ET-1 demonstra sua maior concentração plasmática média às 16 horas, porém sua menor concentração é obtida às 8 horas. Estes resultados nas variações plasmáticas de $\mathrm{LH}, \mathrm{E}_{2}$ e $\mathrm{P}_{4}$ demonstram padrão fisiológico para a espécie estudada. As concentrações plasmáticas periféricas de 
ET-1 tendem às variações de acordo com o ciclo estral. A concentração plasmática de ET-1 foi maior próximo da luteólise e do estro, sendo ambos eventos fisiológicos relacionados à regressão ou ruptura do órgão luteal ${ }^{29}$.

\section{Conclusões}

Nosso trabalho mostra que a endotelina-1 diminuiu a proliferação celular e aumentou a produção de progesterona em cultura de CG de folículos antrais médios (5 a $8 \mathrm{~mm}$ ) in vitro. In vivo observou-se que não há variações nas concentrações plasmáticas deste peptídeo durante o ciclo estral de vacas, desde a ovulação até o $13^{\circ}$ dia do ciclo, considerando como ápice do funcionamento do corpo lúteo, após o qual a luteólise se instala. Podemos concluir que em ovários bovinos a ET-1 pode exercer efeitos locais que não implicam na manutenção inicial do CL e que, em folículos antrais, seu efeito poderia ser considerado atretogênico.

\section{Endothelin-1 effects on steroidogenesis and cellular growth of bovine granulosa cells culture}

\section{Abstract}

Besides the neuroendocrine control of the hypotalamic-hypophisarygonodal axis there are autocrines and paracrines factors that control the growth, selection and ovulation in the mammals. These factors are not well established yet. Aiming to analyze the variations in the endotelin-1plasmatic concentrations in a bovine estral cycle and their effects on the culture of granulosa cells, plasma samples of 5 days $(0,1,3,7$ and 13) from an estral cycle have been analyzed, having as basis the ovulation day (day 0 ) and 3 hours $(8,13,16$ ) of the fourteenth day of the cycle. The variations in the endothelin-1 concentrations were not significant for the days as well as for the hours of the analyzed day. Granulosa cells obtained from antral follicles were cultivated during 24 hours with different concentrations of endothelin. The results demonstrated that the endothelin- 1 acts in a dose-dependent manner stimulating the production of progesterone and inhibiting the cellular growth.

\section{Referências}

1 YANAGISAWA, $M$. et al. A novel potent vasoconstrictor peptide produced by vascular endothelial cells. Nature, n. 332, p. 411-415, 1988.

2 RAKUGI, $\mathrm{H}$. et al. Endothelin inhibits renin release from isolated rat glomeruli. Biochem. Biophys. Res. Commun., v. 155, p. 1244-1247, 1988.

3 FUKUDA, Y.; HIRATA, Y. YOSHIMI, $\mathrm{H}$. Endothelin is a potent secretagogue for atrial natriuretic peptide in cultured rat atrial myocytes. Biochem Biophys Res Commun., v. 155, p. 167-72, 1988.

4 RAE, G. A. et al. Endothelin-1 release eicosanoids from rabbit isolated perfused kidney and spleen. J. Cardiovasc Pharmacol., v. 13, p. 589-592, 1989. Supplement 5.

5 GOETZ, K. L. et al. Cardiovascular, renal, and 1988. 621-622, 1991 p. $1909-1914,1991$.
Key-words: Steroidogenesis. Granulosa cells. Catte.

Endothelin-1.

Follicular development. conscious dogs. Am. J. Physiol., v. 255, p. 1064-1068

6 MATSUMOTO, $\mathrm{H}$. et al. Abudance of endothelin-3 in rat intestine, pituitary gland and brain. Biochem. Biophys. Res. Commun., v. 164, p. 74-80, 1989.

7 USUKI, S. et al. Endothelin-1 in luteal tissue. Mol. Cel. Endocrinol., v. 80, p. 147-151, 1991.

8 USUKI, S. et al. Endothelin induces DNA polymerase $\alpha$ activity in ovaries of hypophysectomized estrogentreated immature rats. Horm. Metab. Res., v. 23, p.

9 IWAI, M. et al. Endothelin inhibit luteinization of cultured porcine granulosa cells. Endocrinology, v. 129,

10 FRANCHIMONT, P. et al. Effect of mouse epidermal growth factor on DNA and protein synthesis, 
progesterone and inhibin production by bovine granulosa cells in culture. Acta Endocrinol (Copenh), v. 111, p. $122-127,1986$

11 FUKUOKA, $M$. et al. Interleukin-1 inhibits luteinization of porcine granulosa cells in culture. Endocrinology, v. 122, p. 367-369, 1988.

12 VELDHUIS, J. D.; FURLANETTO, R. W. Trophic actions of human somatomedin C/insulin-like growth factor I on ovarian cells: in vitro studies with swine granulosa cells. Endocrinology, v. 116, p. 1235-1242, 1985.

13 KNECHT, M.; CATT, K. J. Modulation of CAMPmediated differentiation in ovarian granulosa cells by epidermal growth factor and platelet-derived growth factor. J. Biol. Chem., v. 258, p. 2789-2794, 1983.

14 LANGHOUT, D. J.; SPICER, L. J.; GEISERT, R. D. Development of a culture system for bovine granulosa cells: effects of growth hormone, estradiol, and gonadotropins on cell proliferation, steroidogenesis, and protein synthesis. J. Anim. Sci.. v. 69, n. 8, p. 3321-3334, 1991.

15 SPICER, L. J.: ALPIZAR, E.; ECHTERNKAMP, S. E. Effects of insulin, insulin-like growth factor $\mathrm{I}$, and gonadotropins on bovine granulosa cell proliferation, progesterone production, estradiol production, and(or) insulin-like growth factor I production in vitro. J. Anim. Sci., v. 71, p. 1232-1241, 1993.

16 BÉLANGER, A.; CARON, S.; PICARD, V. Simultaneous radioimmunoassay of progestins, androgens and estrogens in rat tests. Journal of Steroid and Biochemistry. v. 13, p. 185-190, 1980.

18 GENARO, G.; ROSA-E-SILVA, A. A. M. Setting-up and validation of the radioimmunoassay method for determination of the LH concentration in felines. ARS Veterinária. v. 13, n. 1, p. 44-51, 1997.

19 KAMADA, S. et al. The role of endothelin-1 in regulating human granulosa cells proliferating and steroidogenesis in vitro. Journal of Clinical Endocrinology and Metabolism, v. 80, n. 12, p. 37083714,1995

20 SALAMONSEN, L. A. et al. Mitogenic actions of endothelin and other growth factors in ovine endometrium. Journal of Endocrinology, v. 152, p. 283-290, 1997.

21 KAMADA, S. et al. Direct effect of endothelin-1 on the granulosa cells of the porcine ovary. Journal of Endocrinology, v. 134, p. 59-66, 1992.

22 AARON, J. W.; BILLIG, H.; TSAFRIRI, A. Ovarian follicle atresia: a hormonally controlled apoptotic Process. Endocrine Reviews. v. 15, n. 6, p. 707-724, 1994

23 HUGHES, M. F.; GOROSPE, W. C. Biochemical identification of apoptosis (programmed cell death) in granulosa cells: evidence for a potential mechanism underlying follicular atresia. Endocrinology, v. 129, n. 5, p. 2415-2422, 1991.

24 IRELAND, J. J. ROCHE, J. F. Development of antral follicles in cattle after prostaglandin-induced luteolysis: changes in serum hormones, steroids in follicular fluid, and gonadotropin receptors. Endocrinology, n. 111, p. 2077-2086, 1982

25 MANIKKAM, M.; RAJAMAHENDRAN, R Progesterona-induced atresia of the proestrus dominant follicle in the bovine ovary: changes in diameter, insulinlike growth factor system, aromatase activity, steroid hormones, and apoptotic index. Biology of Reproduction, n. 57, p. 580-587, 1997

$26 \mathrm{O}^{\prime}$ CONNER, J. L. Peptidase activity in the hypothalamus and pituitary of the rat: fluctuations and possible regulatory role of luteinizing hormone releasing hormone-degrading activity during the estrous cycle. Biology Reproduction, v. 36, p. 855862,1984

27 HAFEZ, E. S. E. Reprodução Animal. 6. ed. São Paulo: Manole, 1995. p. 95-145.

28 MIYAMOTO, A. et al. Prostaglandin $\mathrm{P}_{22}$ promotes the inhibitory action of endothelin- 1 on the bovine luteal function in vitro. Journal of Endocrinology, v. 152, p. R-7-R11, 1997.

29 OHTAMI, A. A. et al. Real-time relationships between intraluteal and plasma concentrations of endothelin oxytocin, and progesterone during prostaglandin F2 alpha-induced luteolysis in the cow. Biology Reproduction, v. 58, p. 103-108, 1998.

30 DE LEAN, A. et al. Characterization of specific receptors for atrial natriuretic factor in bovine adrenal zone glomerulosa. Life Sci... v. 35, p. 2311-2318, 1984.

31 GINTHER, O. J. et al. Selection of the dominant follicle in cattle. Biology of Reproduction, n. 55, p. 1187-1194, 1996.

32 GOSPODAROWICZ, D.; ILL, C. R.; BIRDWELL, C. $R$. Effect of fibroblast and epidermal growth factors on ovarian cell proliferation in vitro. I. Characterization of the reponse of granulosa cells for FGF and EGF. Endocrinology. v. 100, p. 1108-1120, 1977.

33 GOSPODAROWICZ, D.; BIALECK, H. Fibroblast and epidermal growth factors are mitogenic for granulosa cells of rodent, porcine and human origin. Endocrinology. v. 104, p. 409-420, 1979.

34 IRELAND, J. J.: ROCHE, J. F. Development nonovulatory antral follicles in heifers: changes in steroids in follicular fluid and receptors for gonadotropins. Endocrinology, n. 112, p. 150-156, 1983.

35 LOCKSHIN, R. A.; WILLIAMS ,C. M. Programmed cell death II. Endocrine potentiation of the breakdown of the intersegmental muscles of silk-moths. J. Insect Physiol., v. 10, p. 643-649, 1964 
36 MASAKI, T. Endothelins: Homeostatic and Compensatory actions in the circulatory and endocrine systems. Endocrine Reviews, v. 14, n. 3, p. 256-268, 1993

37 MONDSCHEIN, J. S.; SCHORNBERG, D. W. Growths factors modulate gonadotropin receptor induction in granulosa cells culture. Science, n. 211 p. 1179-1181, 1981.

38 MORISHITA, R.; HIGAKI, J.; OGIHARA, T. Endothelin stimulates aldosterone biosynthesis by dispersed rabbit adreno-capsular cells. Biochem. Biophys. Res. Commun., v. 160, p. 628-632, 1989.

39 PANDEY, K. L. et al. Atrial natriuretic factor regulates steroidogenesis responsiveness and cyclic nucleotide levels in mouse Leydig cells in vitro. Biochem. Biophys. Rev. Commun., v. 138, p. 399-404, 1986.

40 PANDEY, K. N. OSTEEN, K. G. INAGAMI, T. Specific receptor-mediated stimulation of progesterone secretion and cGMP accumulation by atrial natriuretic factor in cultured human granulosa-lutein (G-L) cells. Endocrinology, v. 121, p. 1195-1197, 1987.

41 RAJAKOSKI, E. The ovarian follicular system in sexually mature heifers with special reference to seasonal, cyclical, and left-right variations. Acta Endocrinol., n. 34, p. 7-68, 1960. Supplement 52.

42 RALL, L. B.; SCOTT, J.; BELL, G. I. Mouse preproepidermal growth factor synthesis by the kidney and other tissues. Nature, n. 33, p. 228-231, 1995.

43 USUKI, S.; SAITOH, T.; SAWAMURA, T. Increased maternal plasma concentration of endothelin-1 during labor pain or on delivery and the existence of a large amount of endothelin-1 in amniotic fluid. Gynecol. Endocrinol., v. 4, p. 85-97, 1990

44 WEStergaARD, L. G.; ANDERSEN, C. V. Epidermal growth factor in human folicullar fluid. In: HASELTINE, F. P.; FINDLAY, J. K.Growth Factors in Fertility Regulation. (Ed.). Cambridge: Cambridge University, 1991. v. 1, p. 261-269. 